\title{
12 \\ Modeling to support a food industry in the extended enterprise
}

\author{
I. Hunt, Dip. B.Sc. M.Sc. \\ CIMRU (Computer Integrated Manufacturing Research Unit) \\ University College Galway, Ireland. \\ Tel. +353-91-750414, Fax No. +353-91-562894 \\ E-mail: Ingrid.Hunt@UCG.IE
}

Prof. Dr. R. Carelli, \& Eng. Jorge Pellicer,

Institute of Automation,

University of San Juan,

San Juan, Argentina

Tel. +54-64-213303 Fax No. +54- 64-213672

E-mail: rcarelli@inaut.edu.ar

pellicer@inaut.unsj.edu.ar

Prof. I. Mazon Gonzalez, \& Prof. V.H. Chacón

University of Costa Rica,

San Jose, Costa Rica.

Tel. +506-3836094 Fax No. +506 2242619

E-mail: imazon@pacuare.eie.ucr.ac.cr

\begin{abstract}
This paper highlights research carried out in the Food Industry in Latin America today. The paper discusses the food industry and the role of the supply chain in an extended enterprise concept. It also looks at two ways of modeling a supply chain and a brief description of both is given.
\end{abstract}

\section{Keywords}

Extended Enterprise, Supply Chain Management, Food Industry, Business Process Modeling, $\mathrm{IDEF}_{0}$, Petri Net.

\section{INTRODUCTION}

Enterprises within an extended enterprise concept are always looking for ways to improve their business efficiency. Many approaches are taken, from implementing a total quality management system to redesigning the business processes. All approaches require a real understanding of the business enterprise. One question 
that should be asked when identifying an enterprise is what is the organization trying to achieve with its processes, i.e. its business goals and objectives. Every organization has a number of business processes that it carries out in order to achieve its business objectives; for example processing orders, customer complaints and designing new products, for many organizations the list is endless.

With companies around the world involving themselves in extended enterprise structures many researchers and academics are focusing on business processes and how they can be modeled within this network of enterprises. Before we go on any further we should define what the Extended Enterprise is and also what a business process is. Browne et al. tell us that the manufacturing system can no longer be seen in isolation, it must be seen in the context of the total business and the linkages of the business back through the supplier chain and forward into the customer chain. The challenge for the future is to consider the extended enterprise and facilitate inter-enterprise networking across the value chain. This concept of inter-enterprise networking is called the extended enterprise for short, (Browne, 1995). The extended enterprise extends beyond traditional organizational boundaries. It includes the relationships that an enterprise has with its cuistomers, suppliers, business partners etc. The extended enterprise reflects the high interdependence that exists between organizations as they conduct business.

A business process can be defined as a collection of activities that takes one or more kinds of input and creates an output that is of value to the customer, (Hammer, M., Champy, J., 1995). A business process then is a specific ordering or arranging of work activities across time and place, including the beginning of the process and the end of the process and clearly identifying the inputs and outputs of the business process being modeled. In order to model the supply chain process of an enterprise the model must clearly identify its inputs and outputs.

The most effective way to identify the needed information of the enterprises and obtain access to the enterprises information is through modeling the extended enterprise operation. This should not only cover the business processes involved in the enterprises but also it should identify both their internal and external relationships. Kosanke et al. state that to achieve sufficient flexibility for maintaining the models and keeping them really up-to-date, modeling has to become a tool not only for planning but for operational support as well, (Kosanke et al., 1995).

Business Process Modeling of the supply chain allows the extended enterprise to build a model of its current supply chain process ("as-is") or its proposed supply chain process ("to-be"). The model allows for the supply chain performance to be analyzed. Modeling the supply chain process of any enterprise is an important step in building a more efficient supply chain.

New tools, methods and knowledge for the supply chain of a food industry in the extended enterprise are necessary and they can only be developed by increased cooperation between research institutions, academics, the agribusiness and food industries.

Modeling tools are new for the extended enterprise, therefore when enterprises want to model the business processes of their organization; the tools they use are "borrowed tools". 


\section{THE FOOD INDUSTRY}

The Food Industry was once seen as a low tech and high labor intensive industry. Things are rapidly changing and for once this industry is becoming the focus of many research projects, for example $S C M+{ }^{1}$ and LOGSME ${ }^{2}$.

Both projects have industrial partners that are in the food industry and the research concentrates on the integration of their supply chain.

The food industry is now beginning to realize that integration of their supply chain is an area that will lead to the success of their organization. The creation of supply chain management functions have pulled together disparate parts of this industry and turned them now into cohesive operating units, (Lamey, 1996). The food industry supply chain is defined by Folkerts and Koehorst as a set of interdependent companies that work closely together to manage the flow of goods and services along the value-added chain of agricultural and food products, in order to realize superior customer value at the lowest possible costs, (Folkerts and Koehorst 1997).

Intense competition in the food industry has led to innovative distribution techniques and increased efficiencies, such as enterprise integration all of that benefit the customers.

According to Lamey, the need to provide customers simultaneously with higher service levels at a lower cost whilst building customer loyalty has provided a difficult working environment for the food industry. Part of the solution for success in this industry can be found in re-engineering the supply chain, (Lamey, 1996). Re-engineering the supply chain entails rethinking and redesigning the business processes that make up the supply chain in order to achieve improvements. These improvements include cost, quality, and service improvements. Enterprises within the food industry are becoming more adept at making their supply chains responsive to each other. Integration of information is becoming a vital ingredient for the success of these enterprises. In order for an enterprise to be considered as an extended enterprise then information integration throughout the enterprises is critical. For the food industry this includes information regarding stock levels, customer orders, process orders etc.

\section{THE FOOD INDUSTRY IN LATIN AMERICA}

The food industry is a very important activity now in Latin American countries. This activity primary involves small and medium size enterprises that tend to function independently on a weak capital base. However, the speed of change in both the local and the global market parameters and the complexity of its element forces these enterprises to take bigger and faster steps toward lean, agile, and cost-effective production. Furthermore, the constant changes in product and process technotogies and the increasing pressure for healthier, more nutritious and organic products, and the environment benign production systems with emplasis on waste reduction and energy management enhances this challenge. Additionally, emerging international legislation, particularly relevant in the commercial relationships between other countries, has to be considered.

SCM+ Beyond Supply Chain Management in Food Industry, INCO-DC Project: 950880

2 LOGSME , Logistics to Support Continuous Improvement for SME's in the Virtual Enterprise, Esprit No. 22633. 
In general for many developing sectors i.e. coffee, milk, bananas, tomatoes etc., enterprises seek to work in an extended enterprise concept. This includes wholesalers and retailers, producers and their supply chain, food processors and packers, farmers, transportation and delivery services, working together. Emerging now is the concept of agribusiness, defined as the set of all operations involved in the processing and distribution of the agropecuary products, the production operations within the farm and the storing, processing and distribution of all agropecuary products and their derivatives.

A major facilitator for the coordinating function of an extended enterprise is through Information Technology. Inter-enterprise and inter-enterprise networking across the value chain can be supported by today's advances in computing and telecommunication technologies and they're emerging integration into the Information Superhighway.

For small and medium enterprises the real competitive advantage can only be achieved and sustained through the creation of relationships and strong information links and honest co-working among the enterprises involved in the various steps of the supply chain. These concepts are definitely needed for enterprises, in order for them to efficiently utilize their relevant human, organizational, and business resources and also for them to be able to facilitate the necessary interdependencies between their suppliers (farmers and other materials and services suppliers), manufacturers, distributors, sellers and ultimately customers.

Figure 1 shows a typical supply chain for the food industries in the $\mathrm{SCM}+$ project.

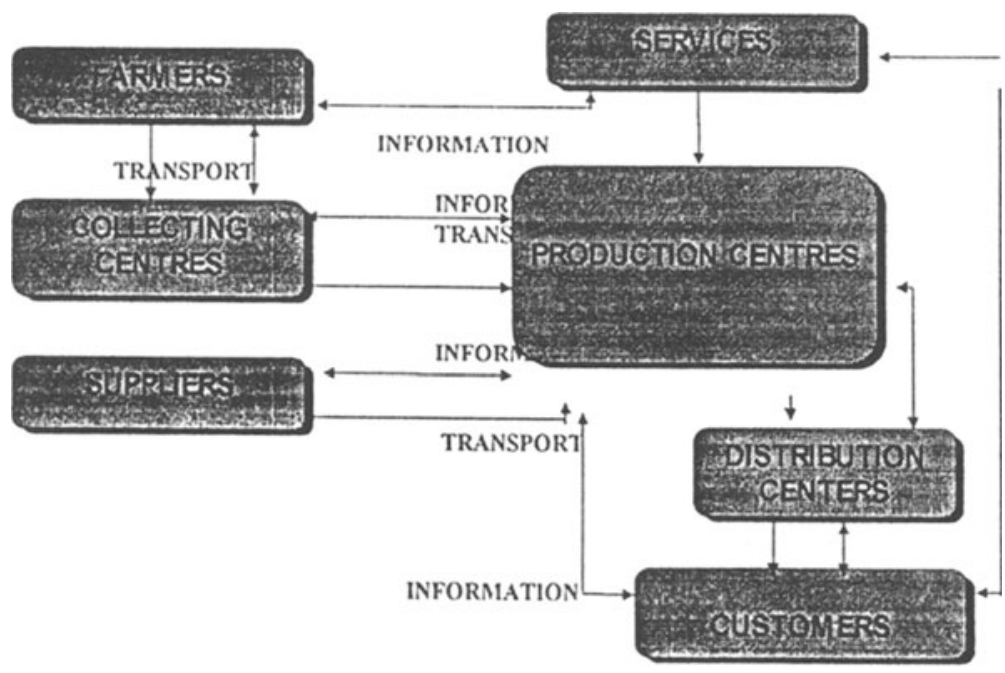

NATIONAL/FOREIGN

Figure 1 Supply Chain, for the Food Industry.

From the point of view of communications and, in general, the information interchange, the big enterprises have a high rate of interactions with suppliers and 
clients. However, they are similar to the small enterprises as they link their information through classical channels, i.e. person to person, telephone or fax.

Many enterprises are imvolved strongly now in Internet applications with their suppliers and are building relationships for electronic data interchange with their big clients (the supermarkets for example). Active sectors in this area for example: coffee and milk suppliers are beginning to commercialize products through the Internet. In the supply chain channel in the food industry it is clear that there are some links stronger and more critical than other links. Customers can be seen as very important links of the chain, they demand final products with high quality and as fast as possible; therefore, the communication with them is critical for maintaining them as good customers. For farmers the communication is also important, they need to have information regarding the production plants and commercialization of the products. Many enterprises are interested in increasing their communications with farmers, as this has been found to be the weakest link of the supply chain.

To implement a data communication infrastructure to support an extended enterprise there are several difficulties depending on the links of the supply chain. In order to study the feasibility for applying the extended enterprise concept, it is of critical importance to know the current social aspects of the enterprises who are involved, considering them as reference case of the agricultural processed food companies of their region. For the industries investigated in the $\mathrm{SCM}+$ project it was found that many managers in developing countries have very little information regarding the extended enterprise. Similarly, the training and the courses planned in-house in enterprises do not include a strong program for information system technologies In general technical personnel are not prepared for extended enterprise operations.

For large clients and critical suppliers it can be easy to implement good information channels. For many members of the extended enterprise the information transmitted to and from each other is very different. In any case, it is very important to have an inner data communications infrastructure that may support each enterprises communications need. For many food industries voice infrastructure communication between the enterprises is acceptable and is in accordance with the normal requirements of any enterprise.

\section{THE SUPPLYCHAIN MODEL}

The supply chain used as an example for this writing could be seen as a complex web of interrelated processes and systems - sometimes the very complexity of an enterprise defeats any attempt to improve or transform it. Production, processing, supply and distribution all used to be regarded as individual processes; nowadays the food supply chain is rapidly becoming an integrated system with each of these links in the chain having interconnected systems.

Modeling the supply chain process therefore simplifies the way we see the complex business process, making the supply chain a real process allowing us to understand and communicate the activities within the supply chain. The food supply chains can vary considerably as they can be seen to be highly dependent on historical and cultural aspects as well as regulatory environments. Government legislation plays a major role in the food supply chain also.

$\mathrm{IDEF}_{0}$ (Integration Definition for Function Modelling) and Petri Net are the modeling tools used to support the food industries involved in the SCM+ project. The model focuses on the different links in the chain, which are required to manage the supply chain process.

$\mathrm{IDEF}_{0}$ comprises of a set of methods that can assist in understanding a complex subject. It uses top-down decomposition to break-up complex topics into small 
pieces which can be more readily understood and which are set in their proper context with respect to system elements. $\mathrm{IDEF}_{0}$ provides the ability to show what is being done within a process, what connects the activities and what constrains the activities. It uses a structured set of guidelines based around hierarchical decomposition, with excellent guidance on abstraction at higher levels. This $\mathrm{IDEF}_{0}$ model shows a systemic perspective of the supply chain of this food enterprise. Figure 2 shows the top level of the supply chain process, which has been modelled.

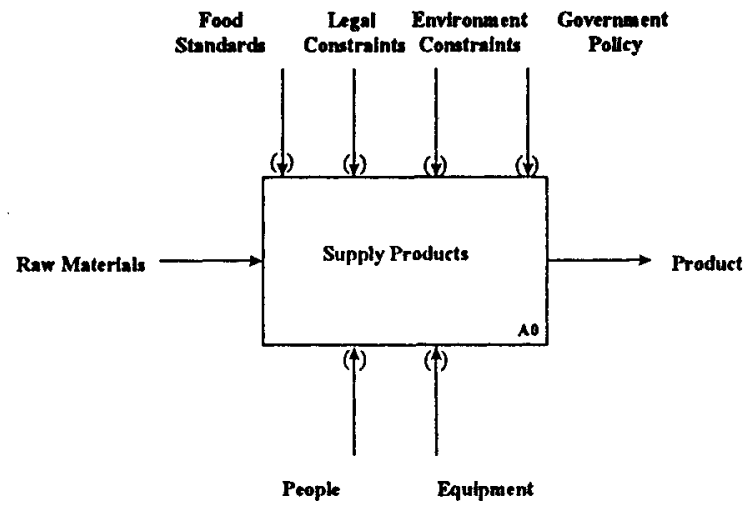

Figure 2 Supply chain model for a food industry in the extended enterprise.

The supply chain model was built on the functional activities of the supply chain process of the food industries and it identifies the products and information that flow between these activities. This level is broken down further to give a clear identification of the inputs, mechanisms, controls and outputs identified for each area of the supply chain process. Using $\mathrm{IDEF}_{0}$ as a modeling technique ensures that the content for any part of a process model under analysis in relation to the whole of the process model is always known, (CAM-1, 1980). Therefore the food organization can focus on the part of a process model it is interested in and develop further levels of detail without losing its context within the whole process. The development of the supply chain process model once again helps this enterprise understand how the processes work within its extended enterprise identifying the links it has with other enterprises. In order to be able to use the information from the model the activities in the process, the process boundaries and the resources used in the supply chain modeling process all need to be understood by those involved in making decisions, within that enterprise. The modeling of the "as-is" situation of the supply chain process gives the enterprise the opportunity to model their enterprise towards a "to-be" situation. It also allows for the process model to be simulated if necessary and then its performance to be analyzed. This process may have to be carried out many times in order for the enterprise to obtain its optimum "to-be" process.

The building of this supply chain process model aids understanding of the actual processes involved in supplying goods to the end customer. It is beyond the scope of this paper to show the complete $\mathrm{IDEF}_{0}$ model of the supply chain under investigation in this research. 


\section{APPROACH TO MODELLING THE SUPPLY CHAIN USING PETRI NETS}

The interrelationship between the enterprises participating in the supply chain, is mainly governed by events which represent the forwarding or reception of relevant information - data, orders, receipt acknowledgments, etc.-, as well as the physical interchange of products. Therefore, the main focus in searching adequate dynamic modeling methodologies and tools should be set on the representation of discreteevent systems. Additionally, continuous system representation could complement the models, when trying to refine the model in order to realistically represent the time lapses involved in some events (Bernhardt et. al., 1994), (Carelli et. al., 1995). The model should be able to capture the dynamic nature of the interactions as well as an adequate representation of the dynamics of each component of the value chain.

In recent years, many techniques for modeling discrete-event systems have been developed. Among them, the following ones can be mentioned: Markov processes and their imbedded Markov chains, Petri Nets, queuing networks, automata and finite-state machines, finitely recursive processes, min-max algebra models, and discrete event simulation and generalized semi-Markov processes (CaO and Ho, 1990), (Ho, 1989). Petri nets represent a tool for modeling systems with interacting and concurrent components. It represents an analytic and graphical approach useful for modeling, analyzing and simulating discrete event dynamic systems.

The next section presents an approach based in Petri nets for dynamically modeling the supply chain in the context of the extended enterprise concept. The model is a simplified version of a real supply chain described in some detail by the SCM+ partners in their research of the food industries supply chains. Different elements of the chain have been considered, including the model of the supplier of raw material, the supplier of supplies and commodities for production, the factory, the clients and the relationships between them.

\section{A CASE STUDY - THE SUPPLIERS-FACTORY-CLIENTS RELATIONSHIP MODEL.}

Characteristics of the chain. Producers of tomatoes from San Juan, Argentina (production: 23,500 Tn) offer their production to the factory in San Juan. The factory places an order (in the model each order is for $500 \mathrm{Tn}$ tomato or 20 trailers) when its warehouses are ready for receiving this load. Mendoza producers $(26,500$ $\mathrm{Tn}$ ) offer their production. The factory also places orders to Mendoza producers when its warehouses are ready for receiving this load. Orders for $69 \mathrm{Tn}$ tin sheet (totaling 3 trailers) are placed when the warehouse is ready to receive this material. With all this raw material, the factory plans to elaborate 50,000 Tn tomato sauce. The Petri net model is presented in Figure 3. The supplier sends these 3 trailers provided he has the materinl available in stock. The Buenos Aires Distribution Centre (hCenterer BA DC) places an order for seven 27.4 Tn trailers of finished products provided its warehouse has free capacity. Provided this processed volume is available at the factory in San Juan, the cargo is sent right away to Buenos Aires. A similar procedure is followed for the Cordoba Distribution Center (hereafter Córdoba DC). The DC-client relationship is described in a similar way. A simplified suppliers-factory-clients relationship model is presented below. 


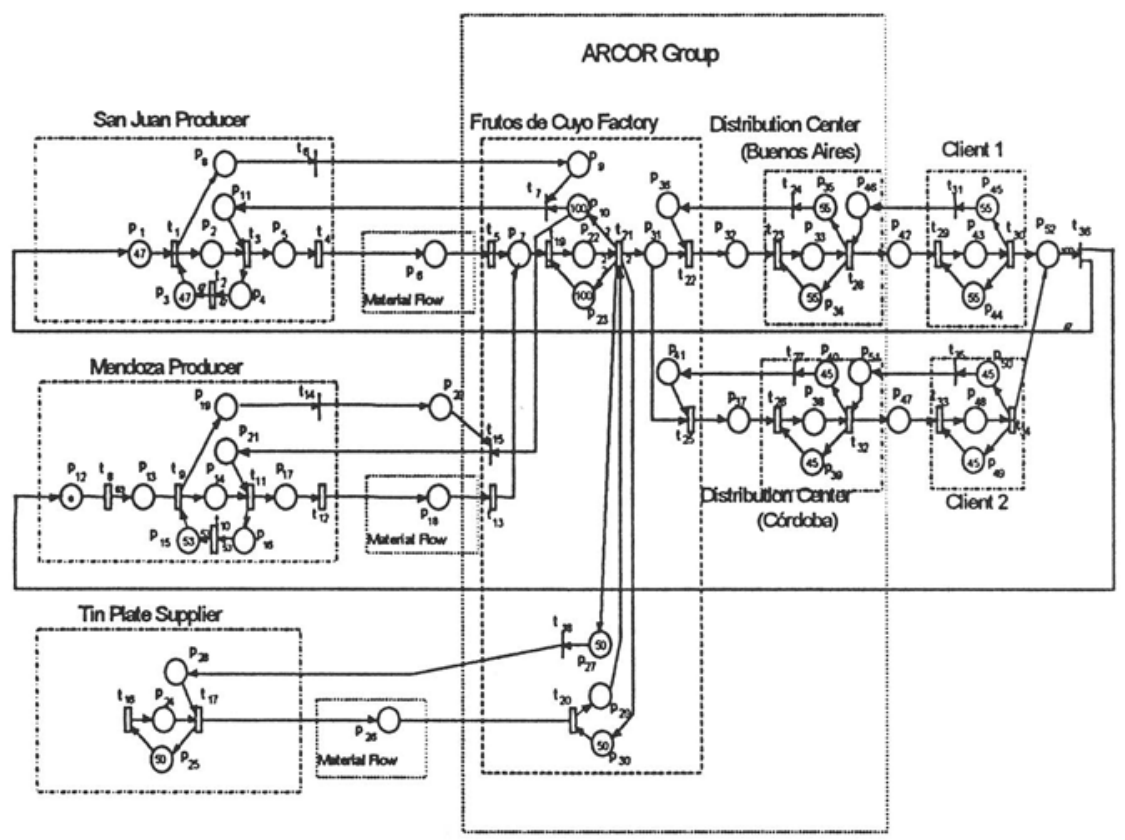

Figure 3 Petri net model of the Tomato Production Chain.

PN elements description. The interpretation of places and transitions of the Petri net model is shown as follows:

\section{Places}

$\mathrm{pl}$ : Initial condition for San Juan producers.

p2: Tomatoes ready to be cropped (SJ producer).

p3: Total tomato volume to produce (SJ producer).

p4: Monitor of tomatoes already cropped (SJ producer)

p5: Tomatoes cropped ready to be shipped (SJ producer).

p6: A cargo of 500 metric tons (Tn) of tomato ( 20 trailers) has been sent by the SJ producer to the factory in San Juan.

p7: Tomato trailers in queue at the factory.

p8: An offer from the SJ producer has been placed.

p9: An offer from the SJ producer has been received at the factory.

p10: Monitor of tomato orders.

pl 1: An order for $500 \mathrm{Tn}$ tomato (20 trailers) has been delivered to the SJ producer.

p12: Initial condition for Mendoza producers.

p13: Production enabling.

p14: Tomatoes ready to be cropped (M producer).

p15: Total tomato volume to produce (M producer).

p16: Monitor of tomatoes already cropped (M producer).

p17: Tomatoes cropped ready to be shipped (M producer). 
p18: A cargo of $500 \mathrm{Tn}$ of tomato (20 trailers) has been sent by the M producer to the factory in San Juan.

p19: An offer from the $M$ producer is issued.

p20: An offer from the $M$ producer has been received at the factory.

p21: An order for $500 \mathrm{Tn}$ tomato (20 trailers) has been delivered to the M producer.

p22: Tomatoes in stock in the factory, ready to be processed.

p23: Quantity of tomato to be processed.

p24: Tin sheet ready to be sent by the supplier.

p25: Tin sheet to be manufactured by the supplier.

p26: A cargo of $69 \mathrm{Tn}$ tin sheet ( 3 trailers) has been sent by the supplier to the San Juan factory.

p27: Monitor of tin sheet orders.

p28: An order for $69 \mathrm{Tn}$ tin sheet has been delivered to the supplier.

p29: Tin sheet in stock at the San Juan factory.

p30: Quantity of tin sheet to be processed.

p31: Tomatoes already processed in the factory.

p32: $191.8 \mathrm{Tn}$ of finished product ( 7 trailers) has been sent from the factory to the BA DC.

p33: Final product in stock at BA DC.

p34: Free capacity of finished products in warehouse at BA DC.

p35: Monitor of finished product orders at BA DC.

p36: An order for 191.8 of finished product is placed by the BA DC.

p37: A cargo of 191.8 of finished product ( 7 trailers) has been sent from $S J$ to the Córdoba DC.

p38: Finished product in stock at Córdoba DC.

p39: Total capacity of finished products in warehouse at Córdoba DC.

p40: Monitor of finished product orders at Córdoba DC.

p41: An order for $191.8 \mathrm{Tn}$ of finished product is placed by the Córdoba DC.

p42: A finished product trailer has been sent from the BA DC to Client 1 .

p43: Finished product in stock at warehouses of Client 1.

p44: Total capacity of finished products in warehouse of Client 1.

p45: Monitor of finished product orders at Client 1.

p46: An order from Client 1 for finished products has been delivered to the BA DC.

p47: A finished product trailer has been sent by Córdoba DC to Client 2 .

p48: Finished product in stock in warehouses of Client 2.

p49: Total capacity of finished products in warehouse of Client 2.

p50: Monitor of finished product orders at Client 2.

p51: An order from Client 2 for finished products has been delivered to the Córdoba DC.

p52: Condition for re-starting.

\section{Transitions}

t1: A San Juan farmer produces $500 \mathrm{Tn}$ of tomatoes

12: A new plantation is prepared by San Juan producer.

t3: 500 Tn tomato is cropped by San Juan farmer.

14: $500 \mathrm{Tn}$ tomato (20 trailers) is sent to the factory.

t5: Trailers from SJ producer arrive at the factory in San Juan.

t6: San Juan producer notices the factory that he has $500 \mathrm{Tn}$ tomatoes available.

77: The factory accepts and places an order for this $500 \mathrm{Tn}$ tomato offers.

18: Enabling for starting production of Mendoza producer.

19: A Mendoza farmer produces $500 \mathrm{Tn}$ of tomatoes.

t10: A new plantation is prepared by $M P$. 
t11: $500 \mathrm{Tn}$ tomato is cropped by MP.

t12: $500 \mathrm{Tn}$ tomato (20 trailers) is sent by MP to the factory in San Juan.

t13: Trailers from Mendoza arrives at the factory.

t14: A MP gives notice to the factory that he has $500 \mathrm{Tn}$ tomato available.

t15: The factory accepts and places an order for this $500 \mathrm{Tn}$ tomato offers.

t16: The tin sheet supplier produces $69 \mathrm{Tn}$ tin sheet.

t17: A cargo of $69 \mathrm{Tn}$ tin sheet ( 3 trailers) is sent by the supplier to the factory.

t18: The factory issues an order for $69 \mathrm{Tn}$ tin sheet.

t19: Tomato trailers are unloaded at the factory's warehouse.

120: Tin sheet trailers from supplier are unloaded at the factory's warehouse.

21: Tomatoes are processed.

122: Seven 27.4 Tn trailers with finished product are sent by the factory to the BA DC.

23: Final product trailers are unloaded at the warehouses of BA DC.

124: The BA DC places an order for seven 27.4 Tn trailers have finished product.

125: Seven 27.4 Tn trailers of finished product are sent by the factory to the Córdoba DC.

126: Finished product trailers are unloaded at the warehouses of the Córdoba DC.

127: The Córdoba DC places an order for seven $27.4 \mathrm{Tn}$ trailers have finished product.

28: Finished product trailers are sent by the BA DC to Client 1 .

29: Finished product trailers are unloaded at warehouses of Client 1.

t30: Client 1 sells the finished products.

t31: Client 1 places an order for seven $27.4 \mathrm{~T}$ trailers of finished product to the BA DC.

132: Final product trailers are sent by the Córdoba DC to Client 2 .

133: Final product trailers are unloaded at the warehouses of Client 2.

t34: Client 2 sells the final products.

t35: Client 2 places an order for seven $27.4 \mathrm{~T}$ trailers of finished product to the Córdoba

DC.

t36: Re-Starting the cycle.

Conflict Resolution. A typical conflict arises when the factory receives offers from a larger number of producers than needed for the planned industrialized production. Therefore, the factory has to decide which producers are to fill the needs. In the Petri net model, this conflict is evidenced by a conflict in transitions tl to $\mathrm{Tn}$ respecting place pl, see Figure 4 . A supervisory model becomes imperative, and this is inserted at a higher Petri net layer.

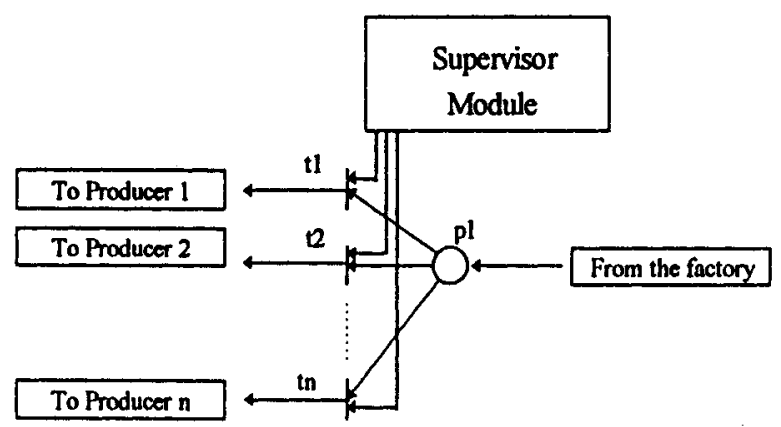

Figure 4 Supervisor Module for solving conflicts.

In the model of extended enterprise concept, certain decision-making mechanisms are necessary in order to modify or fit the model's configuration to any given 
situation. A proposal for solving this, though still under elaboration, consists in supervisor module for modifying the Petri net models for each producer and their interrelationships with the factory.

\section{CONCLUSION}

Up until recently there has been very little food industry research. The food industry never really demanded research in this area before, as they felt it wasn't necessary. Now with the introduction of the extended and virtual enterprise concepts and information technology, many industries including the food industry are looking for ways to adopt these concepts and in doing so improving their supply chain activities.

This paper has highlighted what research has found in the food industry in Latin America. The paper has also tried to show how one industry supply chain was modeled using $\mathrm{DEF}_{0}$ modeling and Petri Net modeling. A first approach for modeling the food supply chain was presented in this paper using $\mathrm{IDEF}_{0}$ and Petri Nets. Petri nets have been proposed as a promising tool for modeling and analyzing the supply chain producer-factory within the extended enterprise concept. Petri nets provide useful models that capture the precedence relationships and structural interactions of stochastic, concurrent and asynchronous events. Conflicts can be modeled and deadlock situations in the system can be detected. Petri nets are mathematical and graphical tools with a well-developed mathematical and practical foundation. Timed Petri nets allow for the quantitative analysis of the supply chain models. As the paper is just highlighting research in this field, the full $\mathrm{IDEF}_{0}$ model is beyond the scope of the paper.

The development of the supply chain process models once again helps this enterprise under investigation and others like it to understand how the processes work within their extended enterprise and importantly identifying the links it has with other enterprises.

\section{ACKNOWLEDGEMENTS}

The authors wish to thank all the members of the SCM+ project, INCO-DC 950880 for giving them the opportunity to write this paper.

\section{REFERENCES}

Bernhardt R., Schreck G., Colombo W., Carelli R. (1994) Integrated Discrete Event and Motion Oriented Simulation for Flexible Manufacturing Systems, Studies in Information and Control, Vol. 3, Nos. 2-3, pp. 209-217.

Browne, J., Sackett, P.J. and Wortmann, J.C. (1995) Future Manufacturing Systems-Towards the Extended Enterprise, Computers in Industry, 25, 235-254.

CAM-1, (1980) Architect's Manual ICAM Definition Method "IDEF-0", Arlington, Texas. 
Cao X.-R. and Ho Y-C. (1990) Models of discrete event dynamic systems, IEEE Control Systems Magazine, Vol.10, No.4.

Carelli R., Colombo W., Bernhardt R., Schreck G. (1995) Discrete Event and Motion - Oriented Simulation for FMS, BASYS '95, Balanced Automation Systems. Architectures and Design Methods, Chapman and Hall, pp. 363-372.

Folkerts, H., Koehorst H., (1997): Challenges in international food supply chains: vertical co-ordination in the European agribusiness and food industries, Supply Chain Management, An International Journal, Vol.2, No.1.

Hammer M., Champy J., (1995) Reengineering the Corporation - A Manifesto for Business Revolution, Nicholas Brealey Publishing.

Kosanke, K., Mollo, M., Naccari, F., Reyneri, C., (1995) Enterprise Engineering with CIMOSA-Application at Fiat, Integrated Manufacturing Systems Engineering, Chapman \& Hall.

Lamey, J., (1996) Supply Chain Management-Best practice and the impact of new partmerships, Financial Times, Management Reports, Pearson Professional.

\section{BIOGRAPHY}

Ingrid Hunt graduated from Sligo Regional Technical College in 1994 with a B.Sc. in Quality Assurance after also completing a Diploma in Electronic Engineering. She graduated from the University of Ulster in 1995 with an M.Sc. in Manufacturing Management. She has worked as a Vendor Engineer and also worked as a Quality Manager in a medical device-manufacturing organization. She joined CIMRU in May 1996 and is currently Project Manager for Esprit and INCODC projects in the area of Logistics and Supply Chain Management. She is currently working on her Ph.D. at CMRU, in the area of Supply Chain Management.

Ricardo Carelli received his Electrical Engineering degree (with honors) from the National University of San Juan (Argentina) in 1976 and the Ph.D. degree in Electrical Engineering from the National University of Mexico (UNAM) in 1989. He is presently Professor of Automatic Control at the National University of San Juan and researchworker of the National Council for Scientific and Technical Research (CONICET). His current research interests are in the fields of robot control, manufacturing systems and artificial intelligence applied to systems control. Dr. Carelli is a member of IEEE and AADECA, the Argentine NMO of IFAC.

Jorge Eduardo Pellicer, received his Electronic Engineering degree (with honors) from the National University of San Juan (Argentina). He is currently pursuing his Master Degree in Control Engineering on Coordination Control of Discrete Event Systems. He is holding a grant from the National Council for Scientific and Technical Research (CONICET) in the subject "Supervisory Control of Discrete Event System". His current research interests are in the fields of Petri Nets, Discrete Event Systems Control and Manufacturing Systems. Ing. Jorge Eduardo Pellicer is a student member of Institute Electrical and Electronics Engineers (IEEE). 
Ismael Mazon graduated from the University of Costa Rica in 1976 in Electrical Engineering and 1982 from University Santa Maria, Chile in Automatic Control. He is presently Cathedratic at the University of Costa Rica, Electrical Engineering School. His current research interest is in the fields of intelligent control systems, automatic control of energy systems, and real time control systems.

Victor H. Chacon graduated from the University of Costa Rica in 1974 in Electrical Engineering and 19790 from CINVESTAV, Mexico in Communications Systems. He is presently Cathedratic at the University of Costa Rica, Electrical Engineering School. His current research interest is in the fields of telematics, data communication systems and local area networks. 